\title{
ESTIMATION OF POSSIBILITY FOR PRODUCING FULL-STRENGTH JOINT OF LARGE STEEL PARTS USING THE METHOD OF AUTOVACUUM BRAZING OF THREADED PROFILE
}

\author{
M.A. POleShCHUK, M.G. ATROShENKo, A.L. PUZRIN and V.L. SHEVTSOV \\ E.O. Paton Electric Welding Institute, NASU
}

11 Bozhenko Str., 03680, Kiev, Ukraine. E-mail: office@paton.kiev.ua

\begin{abstract}
Mechanical properties of brazed threaded joints from similar and dissimilar steels produced by autovacuum brazing method are studied in thread transverse direction. It is determined that tearing strength limit in brazing of low-alloy structural steels corresponds to yield strength of steel after traditional heat treatment. The tearing strength of brazed threaded joints of $12 \mathrm{Kh} 18 \mathrm{~N} 10 \mathrm{~T}$ to $40 \mathrm{Kh}$ steels significantly exceeds the yield strength of stainless steel. Permanent joints, produced by means of thread with further autovacuum brazing, can be recommended for manufacture of parts of critical designation. 11 Ref., 1 Table, 3 Figures.
\end{abstract}

Keywords: autovacuum brazing, threaded joints, dissimilar steels, mechanical properties

Today special brazing methods allow producing brazed seams with strength equal or close to strength of parts to be joined form different steel grades. Such result is achieved at minimum possible width of the brazed seam using brazing filler alloys (BFA) with high melting temperature, since refractory BFA have lager elasticity modulus and provides higher strength to the brazed joint [1, 2].

A technology of receiving of full-strength brazed seams can be used for production of permanent threaded joints in large-sized parts, which should maintain large forces, caused by loads or pressure. In this case required strength of the part along the longitudinal axis is provided by selection of thread of corresponding profile, and that across the axis is determined by brazed joint strength. Such joints can be used for manufacture of the profile parts, including from dissimilar steels, in performance of load bearing seams of rings, forming thick-wall vessels, sections of thickwall pipelines of power installation instead of electroslag or multi-pass arc welding [3].

The brazed threaded joints are used in different branches, for example, aircraft building, oil and gas industry etc. However, earlier applied methods of brazing allow penetration of BFA in the threaded joint only at depth of several turns. In this connection brazing of the threaded joints is carried out only for their sealing [4-6].

A method of autovacuum brazing (AVB) allows increasing the depth of BFA flowing in narrow capillary gap. This method provides for the possibility of joining of metals, including dissimilar ones, by means of filling of pressure seal gap between the parts by BFA. Heating of steel parts to more than $1000{ }^{\circ} \mathrm{C}$ promotes for spontaneous cleaning of metallic surfaces, transformed into the pressure seal gap, from oxide films due to diffusion of oxygen from the surface to metal depth [7]. This process takes place up to the moment when all oxygen, present in the pressure seal gap, diffuses in a metal volume. At that, vacuum is formed in the gap. Spontaneous cleaning from the oxide films and absence of noticeable evaporation of BFA components in pressurized volume promotes for increase of the depth of its penetration into the gap [8].

The aim of present work is an estimation of fundamental possibility for production of the AVbrazed threaded joints. Capability of the BFA to penetration at significant depth in the threaded joint was determined at the first stage, and mechanical properties of the brazed joints, including strength in thread transverse direction, was checked at the second one.

Copper was taken as a BFA for performance of work. It is the most widespread BFA for brazing of carbon and low-alloy steels. Brazing temperature made $1150{ }^{\circ} \mathrm{C}$.

The BFA melting temperature in order to provide high strength of the whole part should be higher than the temperature of quenching of steels used for manufacture of threaded joint, as long as heat treatment of finished part should be proceeded by brazing.

It is a well-known fact that heating of steel in brazing to the temperature significantly higher than quenching one results in grain growth and loss of its ductility and toughness. Special investigations showed that further quenching with tempering of the steel parts, brazed at more than 


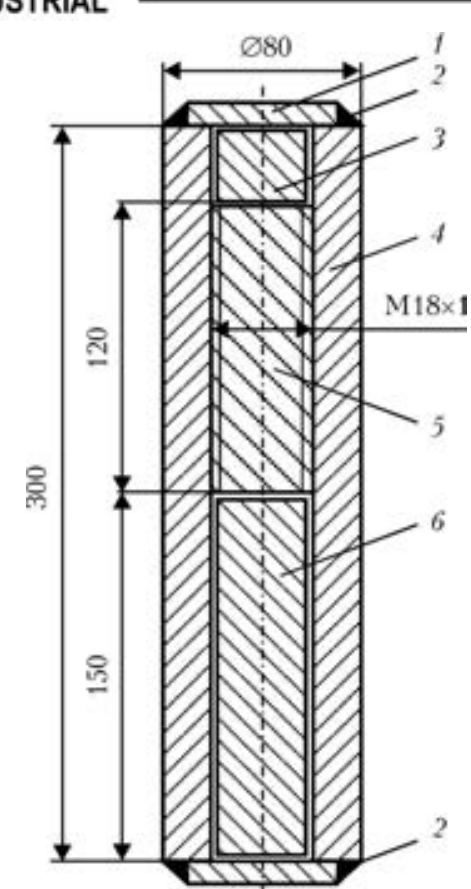

Figure 1. Scheme of sample for AVB in assembly: 1 technological flange; 2 - seal seams; 3 - BFA; 4 - body; 5 - rod with thread; $6-$ smooth rod

$1000{ }^{\circ} \mathrm{C}$, provides for complete reconstruction of metal strength properties as well as rises indices of ductility and toughness in comparison with the same indices of metal, which was not previously subjected to high temperature heating [9].

Special samples of two types were manufactured for experiment performance. One sample included a threaded joint, produced from one grade of steels $(40 \mathrm{Kh})$, and another from different steel classes (40Kh and $12 \mathrm{Kh} 18 \mathrm{~N} 10 \mathrm{~T})$. Bodies of experimental samples were manufactured from round rolled metal of $80 \mathrm{~mm}$ diameter and $300 \mathrm{~mm}$ length. Through-holes of $18 \mathrm{~mm}$ diame-

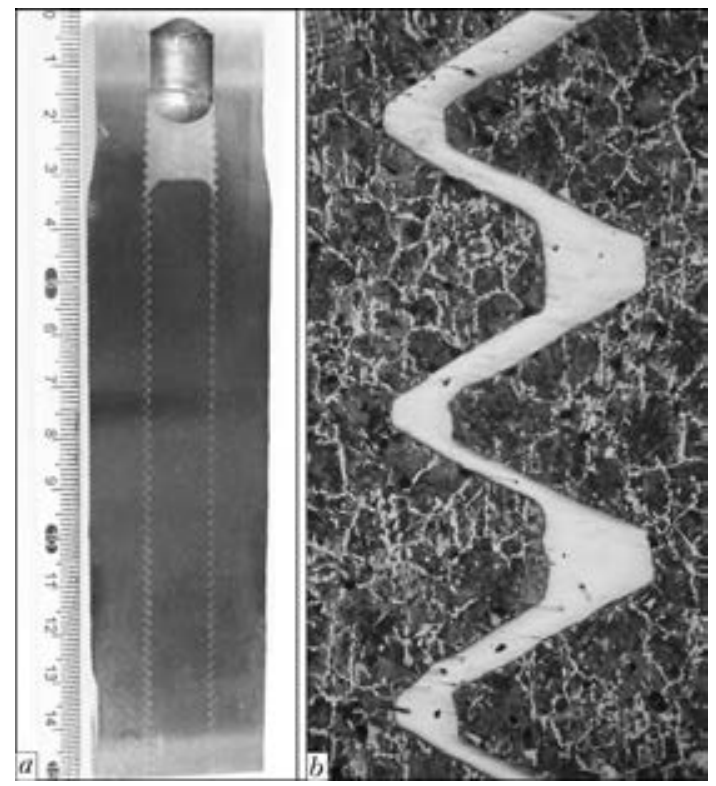

Figure 2. Macrosection of template $(a)$ and microsection of threaded part of brazed $40 \mathrm{Kh}$ sample $(b)$ ter were made in them. Thread $\mathrm{M} 18 \times 1$ was screwed in the middle of length of these holes and the second part remained smooth.

Experimental bodies were produced from steel $40 \mathrm{Kh}$, which after standard heat treatment (quenching in oil with further tempering) provides for mechanical properties of metal for wide range of forgings at the level of requirements of strength category SC-490 [10], in particular for manufacture of parts of critical designation.

Two rods were manufactured for each body. One with M18×1 thread and another with smooth surface, at that the gap between it and body made $0.02 \mathrm{~mm}$ per side.

One set of the rods was manufactured from $40 \mathrm{Kh}$ steel bar of $20 \mathrm{~mm}$ diameter and another was made from stainless steel $12 \mathrm{Kh} 18 \mathrm{~N} 10 \mathrm{~T}$ of the same diameter. M1 copper rod of $15 \mathrm{~mm}$ diameter and $30 \mathrm{~mm}$ length was used as a BFA.

All parts before assembly for brazing were thoroughly washed from emulsion, which was used for machining of the parts. The gaps from both sides were sealed using electric arc welding after assembly of the samples for brazing (Figure 1).

Brazing was carried out in furnace with air atmosphere, the bodies in the furnace were installed vertically, BFA upward.

Brazing thermal cycle was the following: heating to $1150{ }^{\circ} \mathrm{C}, 1 \mathrm{~h}$ holding, cooling at furnace to room temperature. The bodies after brazing were subjected to quenching with tempering using the mode standard for steel $40 \mathrm{Kh}$. Then, the templates of $14 \mathrm{~mm}$ thickness were cut out in the body center along the longitudinal axis.

Visual inspection of these polished templates showed that copper BFA penetrates not only through the thread, but at the whole length of smooth brazing gap in similar sample with rod from $40 \mathrm{Kh}$ steel. No incomplete penetration was found (Figure 2) using lens at ten-fold magnification.

At the same time, the BFA filled the gap only partially in combined sample, and did not penetrate in the smooth gap at all. The reason of this can be a difference in heat expansion of structural and stainless steels. Thus, the difference in heat expansion at $20 \mathrm{~mm}$ length for such steels makes $0.14 \mathrm{~mm}$ and virtual gap before heating in smooth samples is $0.04 \mathrm{~mm}$. However, it can not be a

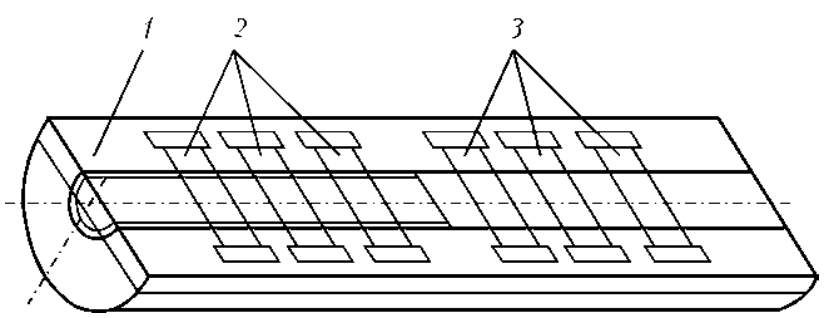

Figure 3. Scheme of cutting out of samples for mechanical tests: 1 - template; 2, 3 - samples with and without thread, respectively 
Results of mechanical tests of base metal after heating for brazing and further heat treatment

\begin{tabular}{||l|c|c|c|}
\hline \multicolumn{1}{|c|}{ Place of sample cutting out } & Yield strength, MPa & Tensile strength, MPa & Elongation, \% \\
\hline Steel 40Kh body & $\frac{540.9-581.8}{561.4}$ & $\frac{771.8-778.4}{775.1}$ & $\frac{17.5-19.1}{18.3}$ \\
\hline Steel 40Kh rod & $\frac{552.6-561.4}{557.0}$ & $\frac{742.2-763.1}{752.7}$ & $\frac{16.2-18.2}{17.2}$ \\
\hline Steel 12Kh18N10T rod & $\frac{207.7-215.0}{211.4}$ & $\frac{555}{555}$ & $\frac{61.3-61.7}{61.5}$ \\
\hline
\end{tabular}

Notes. 1. Minimum and maximum values are given in numerator, average value on three samples - in denominator. 2 . Requirement GOST to $\mathrm{SC} \geq 490$.

single reason of absence of brazed joint formation, since copper is successfully used even for brazing of the parts from carbon steels, preliminary assembled by press fit [11].

The reason also preventing penetration of copper in the narrow gap of combined sample can be dissolving in it of the alloying components of stainless steel, first of all of chromium and nickel, that increases temperature of melting of alloyed copper to the brazing temperature.

The samples for mechanical tests of brazed joints were manufactured from the billets cut out across the longitudinal templates (Figure 3).

The tests were carried out by means of tension of the samples with $8 \mathrm{~mm}$ diameter test portion. At that, it included two brazed joint each, located at $18 \mathrm{~mm}$ distance from each other. Tensile tests promoted fracture along one joint.

Thus, tearing strength made 485.0-500.1 for $40 \mathrm{Kh}$ brazed joint with smooth surface, and that was 412.6-458.4 MPa for joint with thread. The samples from dissimilar steels $40 \mathrm{Kh}+$ 12Kh18N10T with thread had 294.7-323.7 MPa.

Visual examination of the samples after testing showed that the brazed joint failures across the longitudinal axis without plastic strain. Since a calculation value for estimation of part strength is taken as a value of yield strength of the material, from which given part is manufactured, then the results given above should be compared with the base metal yield strength. The results of mechanical tension tests of the samples from base $40 \mathrm{Kh}$ and 12Kh18N10T metals are presented in the Table.

Comparison of the results of tearing strength of the brazed joints with yield strength of the base metal showed that tearing strength of the brazed joint of steel $40 \mathrm{Kh}$ to the same steel with smooth surfaces makes 485-500 MPa. This corresponds to the requirements of standard for SC490, but somewhat lower the yield strength of real samples of steel $40 \mathrm{Kh}$ after heat treatment $(540-580 \mathrm{MPa})$, received in rolling direction. This well-known fact that properties of rolled metal in transverse direction will be lower. Therefore, obtained results of mechanical tearing tests of the smooth samples can be taken as good.
Tearing strength of the brazed joint with thread from similar steel $(40 \mathrm{Kh})$ in direction across its axis was somewhat lower (413$458 \mathrm{MPa}$ ). Lower value of tearing strength across the threaded joint in comparison with the smooth one can be explained by larger width of the gap between parts of the thread.

Joint strength (295-308 MPa) was noticeably higher the stainless steel yield strength (208$215 \mathrm{MPa}$ ) in testing of the brazed samples of $12 \mathrm{Kh} 18 \mathrm{~N} 10 \mathrm{~T}$ to $40 \mathrm{Kh}$ steels with thread.

Therefore, permanent joints, produced with the help of thread and further AVB, can be used for manufacture of parts of critical designation. Copper as a BFA can be efficiently used for production of such type of the joints from structural steels, and only for the threaded joints of relatively small depth in the case of combined ones (stainless-structural steels).

1. Khorunov, V.F. (2008) Principles of brazing of thin wall structures of high alloy steels. Kiev: Naukova Dumka.

2. (1975) Reference book on brazing. Ed. by S.N Lotsmonov. Moscow: Mashinostroenie.

3. Serebryanik, I.P. (2011) Autovacuum noncapillary structural brazing. Kiev: Alfa Reklama.

4. Kuznetsov, V.A. (2004) Determination of pressure gas value in brazing with reinforced gap filling by molten brazing filler alloy. In: Proc. of Seminar on State-of-the-Art and Prospects of Development of Brazing. Moscow: Znanie.

5. Karabanov, V.V., Bokharov, I.O. (2012) Solution of problems of leakproofness and reliability of casing pipes. Neft. Khozyajstoo, 1, 42-45.

6. Muraviov, V.I., Mariin, B.N., Chernyshov, L.V. Method of brazing of thin-wall pipes in telescopic joining. Pat. 2193477 RF. Int. Cl. 23K 1/00. Publ. 27.11.2002.

7. Paton, B.E., Medovar, B.I., Puzrin, L.G. et al. (1968) About solution of air gases in solid metal during spontaneous cleaning of its surface. Doklady $A N$ SSSR, 181(1), 70 .

8. Puzrin, L.G., Bojko, G.A., Atroshenko, M.G. (1975) Autovacuum brazing. Kiev: Znanie.

9. Grigorenko, G.M., Puzrin, A.L., Atroshenko, M.G. et al. (2012) Influence of high-temperature heating on properties of steels in brazing of composite bodies of high pressure blind flange. Sovr. Elektrometallurgiya, 2, 45-50.

10. GOST 8 479-70: Forged pieces of structural carbon and alloy steel. Introd. 01.01.71

11. Brooker, H.R., Beatson, E.V. (1957) Industrial brazing. Moscow: Oborongiz. 